\title{
CHARACTERIZATION OF NATURAL FIBER REINFORCED COMPOSITES-BAMBOO AND SISAL: A REVIEW
}

\author{
Thingujam Jackson Singh ${ }^{1}$, Sutanu Samanta ${ }^{2}$ \\ ${ }^{1}$ Ph D Student, Mechanical Engineering, NERIST, Nirjuli, Arunachal Pradesh, India \\ ${ }^{2}$ Assistant Proffesor, Mechanical Engineering, NERIST, Nirjuli, Arunachal Pradesh, India
}

\begin{abstract}
In recent years, due to the depletion of the non-renewable resources and increasing environmental consciousness, the researchers are working to develop a new material for replacement. Natural fibers like bamboo, sisal, jute, coir, hemp, etc being a strong contender for replacing the synthetic fibers like glass, carbon, etc. from fiber reinforced polymer composites, many researches have been done in the field of natural fiber reinforced polymer composite materials. In this work, a critical review on the characterization of natural fiber (mainly bamboo and sisal fibers) reinforced polymer composite has been presented.
\end{abstract}

Keywords - Natural fiber reinforced polymers (NFRPs), Bamboo fiber, Sisal fiber, Mechanical characterization, thermal characterization, Electrical Characterization, Machining Optimization

\section{INTRODUCTION}

Threat to the environment, depletion and increasing prices of the conventional non renewable engineering materials has forced the researchers to develop natural fiber reinforced polymer composites [1-7]. Natural fibers as reinforcement in polymer composites have many advantages over the synthetic fibers like lower processing price, lower density, higher strength to weight ratio, higher specific properties, etc. These are also renewable and biodegradable. Due to this enhanced properties, the natural fiber reinforced composites are being increasingly used in many engineering applications like sliding panels, bearings, linkages, bushings, etc. [8]. Instead of the superior properties to their synthetic counterparts, the potential of using natural fibers as reinforcements in the composite material is much limited because of their incompatibility with the hydrophobic polymer matrix, their higher affinity to moisture and tendency to form aggregates during processing. Due to this, a proper characterization of natural fiber reinforced composites is very much essential for its application as an engineering material.

Many research works regarding the characterization of natural fiber reinforced composites have been reported in the recent years. In the following sections of the literature, a critical review of these research works mainly on bamboo and sisal fibers have been mentioned.

\section{CHARACTERIZATION OF BAMBOO FIBER REINFORCED COMPOSITE}

Bamboo is one of the most important renewable, fast growing natural resource which can be used as a replacement for the non renewable synthetic fibers in the polymer composites. The en- hanced mechanical and thermal properties, structures, availability of different techniques of fiber extraction and chemical treatment made the bamboo fiber more flexible for its application in the composite materials [9-11]. Many research works have been done on the characterization of bamboo fiber reinforced composites. The literature of these research works are mentioned in the following sub-sections.

\subsection{Mechanical Characterization of Bamboo Fiber}

\section{Reinforced Polymer Composites (BPCs)}

Instead of their superior properties, the application of bamboo fibers in polymer composites is very much limited due to its hydrophilic nature which hinders the bonding with the hydrophobic polymers. Hence, in the recent times, many researchers have worked to modify the bamboo fiber surface. Alkali $(\mathrm{NaOH})$ treatment (mercerization) is one of the commonly used techniques for extracting and surface modification of the bamboo fibers [12-13]. The degree of surface modification varies with the concentration of the alkali solution [14]. The alkali treatment helps in removing the hemicelluloses and the lignin parts from the bamboo fiber and also results in an increase in its fibrillation. These lead to an increase of the surface area for interacting with the polymer matrix which in turn increased the fiber/matrix interface adhesion. Thus, the mechanical properties of the composite got improved [15-17]. The effects of alkali treatment on the mechanical properties of the BPCs are shown in the figure 1 and 2 . Treatment of the bamboo fiber with the coupling agents like silane (KH560) can also improve the fiber/matrix adhesion by forming a chemical links between the polymer matrix and the cellulose fiber with the help of silane molecules [18]. It has the tendency to significantly improve the 
tensile strength and the values of the elongation at break.

The wood based polymer composites (WPCs) are subjected to photo-degradation and weathering due to the UV radiation and moisture absorption and thus resulted in a loss of strength [1920]. Since, bamboo polymer composites (BPCs) belong to the WPCs, it is essential to improve its photo-stability and weathering effect. When bamboo is soaked in the distilled water for 144 $\mathrm{h}$ and allow it to absorb $81.2 \%$ moisture by its dry weight, its tensile strength and modulus were reduced by $37 \%$ and nearly $50 \%$ respectively, thereby, causing its transverse

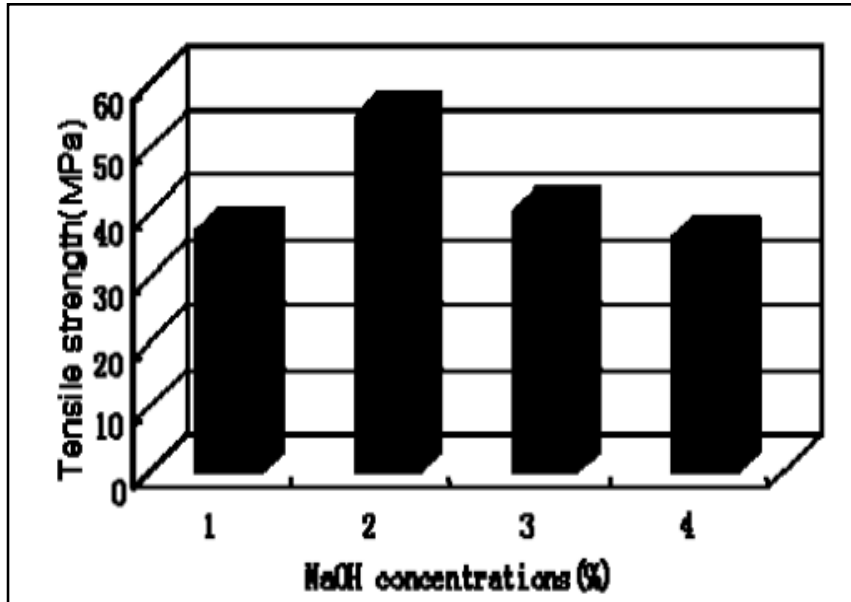

Fig 1 Variation of Tensile strength of bamboo fiber composite with alkali $(\mathrm{NaOH})$ concentration [15]

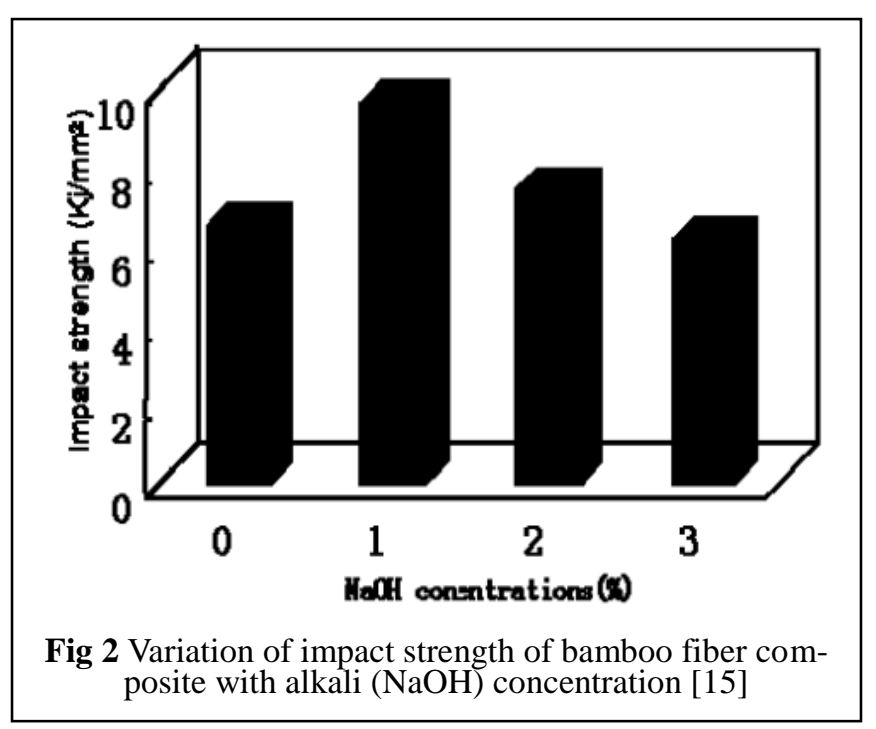

dimension to swell up to $6 \%$ due to the soaking of moisture [21]. The moisture absorption not only affects the properties of the polymer matrix and natural fibers, but also damaged the fiber/matrix interface which caused poor stress transfer efficiency from matrix to reinforced fibers [22]. In a study, the researchers have reported the acetylation treatment of the bamboo fibers for improving the weathering effect of BPCs [23]. This improvement in the weathering effect can be attributed to the reduction of water absorption by the fiber due to the acetylation treatment. In another study, the researchers have used MAH-g$\mathrm{pp}$ in the filler matrix interface to enhance adhesion between the bamboo fiber and the polymer matrix [24]. The MAH-g-pp acts as a compatibilizer and help in increasing the surface area of the spread phase of the polymer matrix in contact with the fiber and hence resulted in a better matrix/fiber adhesion.

The process for extracting bamboo fibers effects the mechanical properties of the bamboo fiber based composites. Researchers have developed several fiber extracting techniques like steam explosion. The tensile strength and modulus of the BPCs were found to increase by 15 and $30 \%$ respectively when the fibers were extracted by steam explosion techniques [25]. On the other hand, when the fibers were chemically extracted using $\mathrm{HNO}_{3}-\mathrm{KClO}_{3}$ and sulphuric acid, the tensile and young's modulus were found much higher than their counterparts [26]. The wetting parameter of the fiber with the matrix also significantly influenced the mechanical properties of the bamboo fiber reinforced composite material [27].

The mechanical properties of the BPCs are greatly influenced by both the fiber length and the fiber volume fraction. In a research work, the researchers have characterized the fracture behavior of BPCs based on its fiber length and the vol. fraction [28]. The fiber length of 4,7 and $10 \mathrm{~mm}$ were investigated. The fiber length of $10 \mathrm{~mm}$ with a fiber content of $50 \mathrm{vol}$. \% exhibited the highest fracture toughness. With the short fiber length, the stress transfer from the matrix to the fiber was not efficient. Also, when the fiber loading is higher, the wetting of the fiber with matrix become lesser and thus weakens the fiber/matrix interface.

In BPCs, the fracture occurs mainly due to the cracking behavior of the matrix surrounding the fiber bundle. In an interesting work, the researchers have developed a technique in which the crack propagation of the BFRCs was significantly reduced by introducing the micro-fibrillated cellulose (MFC) in the polymer matrix as a secondary reinforcement phase [29, 30]. In another study, the researchers have reported the effect of MFCs on the strain energy behavior of bamboo fiber reinforced PLA composite [31]. These improvements in the mechanical properties of the composite were attributed to the inter-locking property of the MFCs, which created a hierarchy of reinforcement, where the bamboo fiber bundles were the primary load-carrying agent and MFCs, the interface in the polymer matrix around the bamboo fiber that prevents sudden crack growth.

Though the bamboo fiber reinforced polymer composites are quite attractive in nature, still they possess lower modulus, strength and moisture resistivity compared to those of synthetic fiber reinforced composites like GFRP. The hybridization of the bamboo fiber composites with synthetic fiber like glass fiber, carbon fiber, etc. can improve various mechanical properties of the composite materials $[32,33]$. The improvement in the me- 
chanical properties can be attributed to the replacement weaker and less stiff bamboo fiber by stronger and stiffer E-glass fiber. Also, the improvement in the aging properties of the composite is attributed to the negligible moisture absorption behavior of E-glass fiber.

\subsection{Thermal Characterization of BPCs}

It is very essential to know the thermal characteristics of the bamboo fiber reinforced composites (BFRCs) for its applications in the extreme temperature conditions. Very few researchers have presented the thermal characterization of the BFRCs. The mercerization process has resulted in an increase in the thermal properties of the BFRCs [14, 17, 24, 34]. With the alkali treatment, bonding between the cellulose molecules in the fibers increases while making a decrease in the affinity of the bamboo fiber towards water. With this process, crystalline nature of the fiber increases. These factors resulted in an increase of the thermal properties of the BFRCs. The inclusion of MA-gpp compatiblizer had resulted in an increase of melting temperature of the BPCs.

\subsection{Electrical Characterization of BPCs}

In the recent years, the uses of conventional material like glass fiber reinforced polymers (GFRPs) have threatened the environmental eco-system since they can't be easily decomposed. The bio-degradable and eco friendly material like bamboo fiber can be used as a replacement of synthetic fibers in the electrical appliances [35]. Bamboo fiber/ice composite materials possess superior insulating properties and can be used as an electrical insulator in the cryogenic region [36-38]. The A.C. breakdown strength of the bamboo fiber depends mainly on the water content. If the water inside the fiber is converted to ice, the A.C. breakdown strength significantly increases.

In another study, the researchers have reported the effect of orientation and mercerization of bamboo fibers on the electrical properties of the bamboo fiber reinforced epoxy composite [39]. It was found that the dielectric constants of the composite with fiber oriented at $90^{\circ}$ to the electric field were higher than that of $0^{\circ}$ orientated composite. It was due to the decrease in orientation polarization of the polar groups present in the lingocellulosic fibers. Further with the mercerization of fibers, the absorption of water by the bamboo fiber was significantly reduced and correspondingly improves the dielectric properties of the composite.

\section{CHARACTERIZATION OF SISAL FIBER REIN- FORCED POLYMER COMPOSITE}

Sisal fiber is one of the widely used natural fibers and is obtained from the leaves of sisal plant (Agave Sisalana). It was reported that about 200-250 leaves were produced by a single sisal plant and each leaf consists of 1000-12700 fiber bundles which are made up of $4 \%$ fiber, $0.75 \%$ cuticle, $8 \%$ dry matter and $87.25 \%$ water [40]. The sisal leaf consists of three types of fibers viz., mechanical, ribbon and xylem fibers [41]. The mechanical fibers were mainly extracted from the peripheral part of the leaf. Many researchers have reported about the methods used in the processing of sisal fibers [40, 42]. Lot of research works have been done on the characterization of sisal fiber reinforced composites. The literature of these works is mentioned in the following sub-sections.

\subsection{Mechanical Characterization of Sisal Fiber Rein-} forced Polymer Composites (SFRPs)

Table 1: Physical and Mechanical Properties of Sisal Fibers with Various Treatments [48]

\begin{tabular}{|c|c|c|c|c|c|c|}
\hline Fibers & 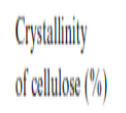 & $\begin{array}{l}\text { Weidith loss after } \\
\text { Iradiment( (\%) }\end{array}$ & $\begin{array}{l}\text { Densily } \\
\text { (g(min') }\end{array}$ & $\begin{array}{l}\text { Tensile strength } \\
\left(M_{\text {Pa }}\right)\end{array}$ & $\begin{array}{l}\text { Youngs moddus } \\
\left(\mathrm{CPP}_{\mathrm{P}}\right)\end{array}$ & $\begin{array}{l}\text { Elongation at } \\
\text { break }(\%)\end{array}$ \\
\hline UTSF & 028 & & 1.29 & $391,1 \pm 4,2.2$ & $15.0 \pm 0.9$ & $25 \pm 0.3$ \\
\hline ATSF & 61.4 & 13.5 & 1.27 & $495.6 \pm 0.10 .1$ & $12.9 \pm 0.8$ & $38 \pm 0.4$ \\
\hline ACSF & (6.8 & 8.2 & 1.32 & $432, \pm \pm 2,3$ & $4.5 \pm 0.3$ & $8.3 \pm 0.7$ \\
\hline ANSF & 58.3 & & - & $37(8.8 \pm 31.4$ & $\| 1.3 \pm 0.8$ & $4.5 \pm 0.3$ \\
\hline SCSF & 35.6 & & - & $387,534,4,5$ & $12.6 \pm 0.6$ & 4.7.1.4. \\
\hline HTSF & 60.2 & 1.6 & $|.3|$ & 33.1 .142 .3 & $15.5 \pm 0.8$ & $3.5 \pm 0.2$ \\
\hline
\end{tabular}

MPa = megapascal, $G P a=$ gigapascal

The mechanical properties of the sisal fiber reinforced polymer composite are largely influenced by the fiber mechanical properties. In some of the studies, the researchers had analyzed the mechanical behaviors of the sisal fibers [43-45]. As in the case of other natural fiber composites, the mechanical properties and the fracture behavior of SFRPs were also significantly influenced by the fiber/matrix interfacial adhesion [46]. A good fiber/matrix interfacial adhesion yields superior mechanical properties of SFRPs.

Many research works have been done for improving the sisal fiber/matrix interfacial adhesion. The sisal fiber is hydrophilic in nature [47]. So, in order to improve the interfacial adhesion, the surface of the sisal fiber needs to be modified. The polar groups present in the natural fiber reinforced thermosetting composites are the main reason behind the good adhesion between the fiber and the matrix. But, on the other hand, no reaction can take place between the fiber and matrix in the case of the thermo-plastic composite, and thus, surface modification of fibers are needed to be done. The researchers have reported the effect of fiber treatment, both chemically and physically, on the mechanical behavior of the SFRPs [48-51]. The heat treatment of fibers increased the crystallinity of the fiber and thus increased the stiffness of the composite. The table 1 gives the effect of various fiber treatments on the mechanical properties of the sisal fibers. 
The alkali treatment helped in removing the hemicelluloses and lignin part, thus leading to the increase of cellulose content and fibrillation. This fibrillation helps in improving the fiber/matrix interfacial adhesion of the composite. On the other hand, acetylation of the sisal fiber helped in reducing water absorption and results in the high impact performance.

The mercerization of the sisal fiber under tension has resulted in the improvement of fracture stress and young's modulus of the composite [52]. The application of tension during the mercerization process prevents the shrinkage of the fiber during soaking and also decreases the microfibrillar angle resulting in the improved alignment of the fibrils along the fiber axis. Therefore, the fiber strength and stiffness too got increased.

Other than the treatment of the fiber chemically, the fiber surface can also be modified by surface coating. In an interesting study, the researchers have modified the sisal fiber by admicellar polymerization with a poly (methyl methacrylate) film coating in order to enhance the fiber/matrix adhesion of polymer composite for improving the mechanical properties [53]. The figure 3 shows the ion pairing mechanism.

It was found that the hydrophobic polymer film formed by the admicellar polymerization got adhered to the hydrophilic fiber substrate due to the presence of surfactant layer, which interacts with the fiber substrate on one side and to the polymer coating film on the other side. And due to this coating, the fiber surface became hydrophobic in nature thus, enhancing the interfacial adhesion between the fiber and matrix.

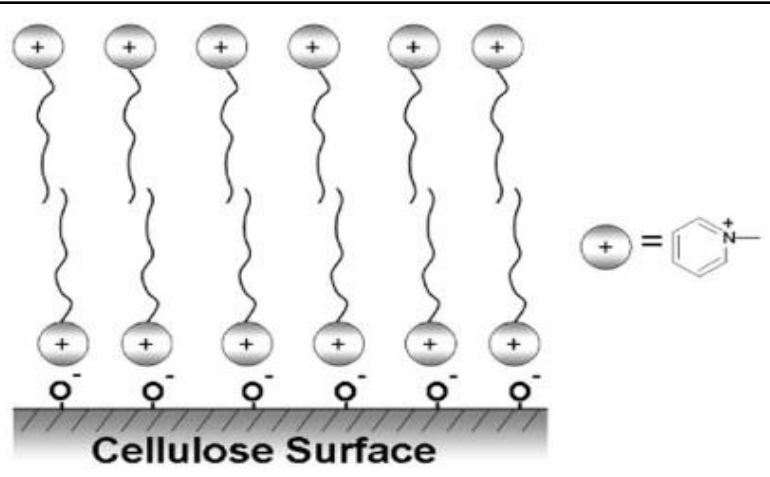

Fig. 3 The ion pairing mechanism between the cellulose anions and the pyridinium cations in admicelle formation [53]

In another study, the researchers have coated the short sisal fiber surface with bacterial cellulose [54]. These resulted in an increase in the surface area of the fiber as much as $800 \%$ as shown in the figure 4 and hence improved the fiber/matrix interface adhesion. This in turn, has improved the mechanical properties of the composite. They further performed the hierarchical reinforcement with the nano-sized bacterial cellulose. This further enhanced the mechanical properties of the composite material.

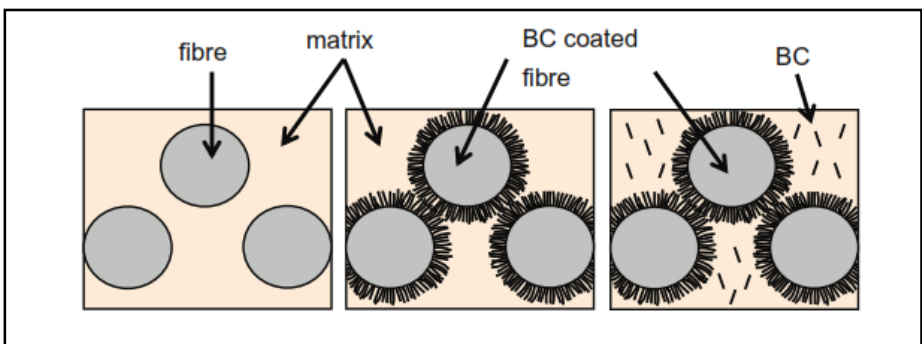

Fig.4 Schematic asahowing Left: conventional FRP Middle: BC coated FRP Right: BC coated hierarchical FRP[54]

Sometimes, the extraction and treatment of the cellulose fibers using harsh chemicals lead to the destruction of the microfibrils [55-57]. It causes degradation of mechanical properties of the fiber. In a work, the researchers have performed the surface micro-fibrillation of the sisal fibers and reported its effect on the mechanical properties of the sisal/aramid fiber reinforced hybrid composite [58]. The surface micro-fibrillation was executed by using a pulp refiner.

In the characterization of natural fiber reinforced polymer composites, the researchers are mainly confined in the fiber modification for improving the composite properties. But in another study, some researchers have done the polymer matrix modification for improving the mechanical properties of the composite [59]. In this work, the polyethylene matrix was treated with the organic peroxide treatment that has resulted in the crosslinking of the polyethylene chains and also grafting of the polyethylene onto the sisal fibers, thereby enhancing the fiber/matrix bonding.

Apart from the fiber surface modifications, the mechanical properties of the sisal fiber reinforced polymer composite were also influenced by the fiber length, fiber loading and also by the nature of the curing cycle of the composite [60-62]. The inclusion of sisal fibers had led to the increase of composite stiffness with an increase in the fiber loading. But the tensile strength and deformation at break were decreased. These were due to the poor adhesion at the fiber/matrix interface and the restriction imposed to the matrix, yielding by the reinforced fiber. During the curing cycle, the application of higher pressure just before the gel point temperature leads to the higher diffusion of matrix between the fibers. This has resulted in higher impact strength. Also, higher the values of the final pressure used at the point of matrix cure, the number of voids present in the composite become lesser.

Like other natural fibers, though the sisal fibers are more attractive due to their superior properties, there are some limitations such as low modulus, poor moisture resistance, etc. Due to these factors, sisal fiber polymers were hybridized with other synthetic fibers like glass fibers, carbon fibers, etc. [59, 63-64]. The hybridization with these synthetic fibers have significantly improved the mechanical properties like tensile strength, 
young's modulus, flexural etc. $[63,64]$ due to the stronger and stiffer characteristics of the synthetic fibers comparing to the sisal fibers.

\subsection{Electrical Characterization of SFRPs}

Only very few research works have been done regarding the electrical characterization of the sisal fiber polymers. Some researchers have reported the effect of the fiber surface treatment, variation of frequency, fiber loading and fiber length on the electrical properties of the composite. With the fiber surface permanganate $\left(\mathrm{KMnO}_{4}\right)$ treatment, hydrophilic nature of the fiber got reduced and thus resulted in the reduction of the dielectric constant and also increased the volume resistivity of the composite [65]. Also, it was reported that the dielectric constant increased with an increase in fiber loading and decreased with the increase in fiber length and frequency [66, 67]. With the increase in fiber loading, the orientation and the interfacial polarization increase due to the presence of polar group of cellulose in fiber and thus the dielectric constant and conductivity got increased.

\subsection{Thermal Characterization of SFRPs}

In comparison to the synthetic fibers like glass fibers, carbon fibers, etc., the thermal stability of natural fibers are low. This relatively lower thermal stability of the natural fibers caused limitation of natural fiber reinforced composite in the higher temperature application [68]. At high temperature, the natural fiber composite undergoes thermal degradation and loses its weight. In order to increase the thermal stability of these composites, a proper research in the thermal characterization is required. Very few research works have been executed regarding the thermal characterization of sisal fiber reinforced polymer composites. In a study, the researchers have reported that the unidirectional reinforcement of the sisal fiber in rubber seed oil (RSO) based polyurethane composite has resulted in an improvement of thermal stability than that of RSO-polyurethane matrix [69]. Though the thermal stability was improved, it was however lesser than the sisal fiber. In another study, the thermal stability of the sisal fiber reinforced polypropylene composite was further improved by adding the flame retardants like ammonium polyphosphate (APP), zinc borate $(\mathrm{Zb}), \mathrm{Mg}(\mathrm{OH})_{2}$, etc. [70]. The interaction of APP with $\mathrm{Mg}(\mathrm{OH})_{2}$ has resulted in the formation of magnesium phosphate glass and $\mathrm{MgO}$ like ceramics which acted as the thermal barrier and resulted in the increase of thermal stability of the composite. It was also reported that the hybridization of the sisal fiber composite with the synthetic fiber like glass resulted in the improvement of the thermal properties like thermal conductivity, diffusivity, etc. due to the presence of $\mathrm{Fe}^{2+}$ ions in the glass fibers [71].

\section{MACHINING CHARACTERIZATION OF NFRPS}

Since the natural fibers are replacing the synthetic fibers due to their superior qualities, it has become very essential to optimize the machining parameters of the natural fiber based composites for enhancing its performance in the machining applications. Though a lot of research works have already been done regarding the optimization of machining of synthetic fiber based composites, only very few works have been reported for the optimization of machining parameters of the natural fiber reinforced polymer composites. Some researchers have also reported that the natural fiber composites possess the potential to replace the synthetic fiber composite like GFRP in many machining applications [72]. In a study, the researchers have reported the optimization of machining parameters in drilling hemp fiber reinforced composite to maximize the tensile strength using design experiments [73]. Taguchi and ANOVA analysis were used to determine the factors and the combination of factors that affect the delamination and tensile strength of the drilled hemp fiber composite. The feed rate and cutting speed were found to contribute maximum to affect the delamination and tensile strength properties.

In another study, the researchers had reported the optimization of polyester composite reinforced with jute fabric [74]. A comparison of machinability of the composites with untreated and treated fiber was done. ANOVA analysis was performed and found that delamination factor was reduced slightly due to alkali treatment. It has also been observed that the alkali treatment have reduced the push down delamination more than the peel up delamination.

Though natural fiber composites are considered as a superior material for the structural application due to their inherent properties, still there are problems regarding the milling of this material like surface roughness problem, delamination problem, etc. coupled with the characteristics of the material and cutting parameters. In a research work, the researchers have evaluated the cutting parameters (cutting velocity and feed rate) in milling and the influence of the fibers under delamination factor and surface roughness [75]. In this study, the Taguchi and ANOVA analysis were performed to optimize the cutting parameters. Also, the results were compared with that of GFRP.

\section{CONCLUSIONS}

A critical review of the characterization for natural fiber reinforced composite: bamboo and sisal, is presented in this literature. Many research works have been reported. The mechanical properties of the natural fiber composites (bamboo, sisal) primarily depend upon the fiber/matrix interfacial adhesion. Though the natural fibers are superior in properties, but due to its hydrophilic nature, it possesses poor bonding nature with the hydrophobic polymer matrix. This has resulted in the degradation of its mechanical properties. Many research works regarding the surface modification of the fibers, both chemically and physically, have been reported for enhancing the fiber/matrix interfacial interaction. The fiber length, loading and its moisture absorption capacity also influence the mechanical properties of the natural fiber reinforced composites. The optimum fiber length, loading and low moisture absorption nature of the fibers have improved the mechanical properties of the composite. 
Some of the research works related to thermal characterization were also reported. The natural fiber composites are also subjected to weight loss due to thermal degradation at higher temperature. The addition of flame retardants have resulted in the increase of thermal stability of the composite.

The natural fiber reinforced composites got high potential of replacing the conventional material used in the electrical appliances. Research works regarding the use of natural fiber composites as the electrical resistance are also reported. Only very few research works on the machining optimizations of the natural composite materials have been reported.

\section{FUTURE CHALLENGES}

1. Though bamboo fiber possesses superior properties than those of the synthetic fibers, but the mechanical properties of the BFRPs are still lagging behind than those synthetic fiber reinforced composites. In order to improve this, the fiber/matrix interfacial interaction is needed to be improved further using different methods.

2. Researchers are needed to come up with new techniques to further enhance the thermal stability of the natural fiber composites for its application at higher temperature applications.

3. The A.C. current breakdown value of the natural composites is still low and thus it is needed to be further improved for its application as electrical resistors.

4. To the extent of the author's knowledge, the hardness characterizations of both the bamboo and sisal fiber reinforced composites were hardly performed. So researchers are required to do more research in this area.

5. As far as the extent of this literature survey, only very few research works have been done regarding the machining parameter optimization for machining the natural fiber composites. More research works are still in need to be executed in order improve the machining performance of the natural fiber reinforced composites.

\section{REFERENCES}

[1] M. Jawaid, K.H.P.S Abdul, "Cellulosic/synthetic fibre reinforced polymer hybrid composites: a review" Carbohyd Polym vol. 86 pp. 1-18, 2011.

[2] D. Puglia, J. Biagiotti, J. M. Kenny, "A review on natural fibre-based composites - part II,“ J Nat Fibres vol. 1 pp. 23-65, 2005.

[3] K.H.P.S. Abdul, I.U.H. Bhat, M. Jawaid, A. Zaidon, D. Hermawan, Y.S. Hadi, "Bamboo fibre reinforced biocomposites: A review,“ Materials and Design Vol. 42 pp. 353-368, 2012.

[4] Yan Li, Yiu-Wing Mai, Lin Ye, "Sisal fibre and its composites: a review of recent developments, " Composites Science and Technology Vol.60 pp. 2037-2055, 2000.

[5] S. Mishra, A.K. Mohanty, L.T. Drzal, M. Mishra, G. Hinrichsen, "A review on pineapple leaf fibers, sisal fibers and their biocomposites. Macromol" Mater. Eng.
Vol. 289, pp. 955, 2004.

[6] P. Wambua, J. Ivens, I. Verpoest, "Natural fibers: Can they replace glass in fiber reinforced plastics" Compos. Sci. Technol. Vol. 63, pp. 1259-1264, 2003.

[7] C.G. Silva, E. Frollini, "Proceedings of Science \& Technology of Biomass, Advances and Challenges,“ Rome, 2007.

[8] N. Chand, M. Fahim, "Tribology of Natural Fiber Polymer Composites" Hardcover ed., 2008.

[9] K. Kitagawa, Ishiaku, M. Mizoguchi, H. Hamada, "Bamboo-based ecocomposites and their potential applications in natural fibres, biopolymers, and biocomposites, “2005 [chapter 11].

[10] S. Amada, Y. Ichikawa, T. Munekata, Y. Nagase, H. Shimuzu,"Fibre texture and mechanical graded structure of bamboo. Compos,“ Part B- Eng., Vol. 28, pp.13-20, 1997.

[11] M.R.K. Murali, R.K. Mohana, "Extraction and tensile properties of natural fibers: Vakka, date and bamboo," Composite Structures, Vol. 77, pp. 288-295, 2007.

[12] A.P. Deshpande, M.B. Rao, C.L. Rao, "Extraction of bamboo fibres and their use as reinforcement in polymeric composites,“ J Appl. Polym. Sci., Vol. 76, pp. 83-92, 2000.

[13] M. Das, D. Chakraborty, "Evaluation of improvement of physical and mechanical properties of bamboo fibres due to alkali treatment,“ J Appl. Polym. Sci., Vol. 107, pp. 522-527, 2008.

[14] M. Das, D. Chakraborty, "Influence of alkali treatment on the fine structure and morphology of bamboo fibres, “ J Appl. Polym. Sci., pp.5050-5056, Vol. 1022006.

[15] Xin-Gong Li; Wu Yi-qiang, "Effect of alkali treated bamboo fibres on mechanical properties of fibrereinforced green composites, “ Mechanic Automation and Control Engineering (MACE), 2010 International Conference, pp.5399-5401, 26-28 June 2010.

[16] M. Das, D. Chakraborty, "Influence of mercerization on the dynamic mechanical properties of bamboo, a natural lignocellulosic composite," Ind Eng. Chem. Res, Vol. 45, pp. 6489-6492 2006.

[17] M. Das, A. Pal, D. Chakraborty, "Effects of mercerization of bamboo strips on mechanical properties of unidirectional bamboo-novolac composites, “J Appl. Polym. Sci.Vol. 100, pp. 238-244, 2006.

[18] Tingju Lu, Man Jiang, Zhongguo Jiang, David Hui, Zeyong Wang, Zuawan Zhou, "Effect of surface modification of bamboo fibers on mechanical properties of cellulose/epoxy composites, " Composites: Part B, Vol. 51, pp. 28-34, 2013.

[19] K.K. Pandey, "Study of the effect of photo-irradiation on the surface chemistry of wood," Polym. Degrad. Stabil., Vol. 90, pp. 2118-2123, 2005.

[20] N.M. Stark, "Effect of weathering cycle and manufacturing method on performance of wood flour and highdensity polyethylene composites,“ J Appl. Polym. Sci., Vol. 100, pp. 3131-3140, 2006. 
[21] V.S. Godbole, S.C. Lakkad, "Effect of water absorption on the mechanical properties of bamboo, “J Mater. Sci. Lett, Vol. 5, pp. 303-304 1986.

[22] Hongyan Chen, Menghe Miao, Xin Ding, "Influence of moisture absorption on the interfacial strength of bamboo/vinyl ester composites, “ Composites: Part A, Vol. 40, pp. 2013-2019, 2009.

[23] Ke-Chang Hung, Yong-Long Chen, Jyh-Horng Wu, "Natural weathering properties of acetylated bamboo plastic composites, “ Polymer Degradation and Stability, Vol. 97, pp. 1680-1685, 2012.

[24] Zhang Ying-Chen, Wu Hong-Yan, Qiu Yi-Ping, "Morphology and properties of hybrid composites based on polypropylene/polylactic acid blend and bamboo fiber,“ Bioresource Technology, Vol. 101, pp. 7944-7950, 2010.

[25] Kazuya Okubo, Toru Fujii, Yuzo Yamamoto, "Development of bamboo based polymer composites and their mechanical properties, “ Composites: Part A, Vol. 35, pp. 377-383, 2004.

[26] Dagang Liu, Tuhua Zhong, Peter R. Chang, Kaifu Li, Qinglin Wu, "Starch composite reinforced by bamboo cellulosic crystal," Bioresource Technology, Vol. 101, pp. 2529-2536 2010.

[27] C.A. Fuentes, L.Q.N. Tran, M.V. Hellemont, V. Janssens, C. Dupont-Gillain, V.A.W Van, I. Verpoest, "Effect of physical adhesion on mechanical behavior of bamboo fiber reinforced thermoplastic composites," Colloids and Surfaces A: Physicochem. Eng. Aspects, Vol. 418, pp. 7$15,2013$.

[28] K.J. Wong, S. Zahi, K.O. Low, C.C. Lim, "Fracture characterization of short bamboo fiber reinforced polyester composites. Materials \& Design, Vol. 31, pp. 4147-4154 2010.

[29] K. Okubo, T. Fujii, N. Yamashita, "Improvement of interfacial adhesion in bamboo polymer composite enhanced with micro-fibrillated cellulose, " JSME Int J Ser A Solid Mech Mater Eng, Vol. 48, pp. 199-204 2005.

[30] T. Fujii, K. Okubo, N. Yamashita, "Development of high performance bamboo composite using micro-fibrillated cellulose," High performance structures and materials (HPSM) Conference, pp. 421-431, 2005.

[31] K. Okubo, T. Fujii, T. Erik, "Multi-scale hybrid biocomposite: Processing and mechanical characterization of bamboo fiber reinforced PLA with micro-fibrillated cellulose, “ Composites: Part A Vol. 40, pp. 469-475, 2009.

[32] M.M. Thwe, K. Liao, "Effects of environmental agingon the mechanical propertiesof bamboo-glass fiber reinforced polymer matrix hybrid composites, " Composites: Part A, Vol. 33, pp. 43-52, 2002.

[33] S.K. Nayak, S. Mohanty, S.K. Samal, "Influence of short bamboo/glass fiber on the thermal, dynamic mechanical and rheological properties of polypropylene hybrid composites, " Materials Science and Engineering A, Vol. 523, pp. 32-38 2009.

[34] M. Das, V.S. Prasad, D. Chakrabarty, "Thermogravimetric and weathering study of novalac resin composites reinforced with mercerized bamboo fiber polymer composites," Polymer Composites, Vol. 30, pp. 1408-1416 2009.

[35] Y. Shiji, N. Shimizu, "Electrical Insulating Properties of Bamboo as a Material of Low Environment Load," Proceedings of the 7th Intemational Conference on Properties and Applications of Dielectric Materials June 1-5 2003 Nagoya.

[36] Y. Shiji, N. Shimizu, "Electrical insulating properties of bamboo-ice composite system at low temperature," Electrical Insulation and Dielectric Phenomena, 2003. Annual Report. Conference on , vol., no., pp.48,51, 1922 Oct. 2003

[37] Y. Shiji, Y. Muramoto, N. Shimizu, "Effect of water distribution on breakdown properties of bamboo-ice composite system at cryogenic region," Solid Dielectrics, 2004. ICSD 2004. Proceedings of the 2004 IEEE International Conference on , vol.1, no., pp.470,473 Vol.1, 59 July 2004

[38] Y. Shiji, Y. Muramoto, N. Shimizu, "AC breakdown properties of bamboo pulp-ice composite system at cryogenic temperature," Dielectrics and Electrical Insulation, IEEE Transactions on , vol.14, no.2, pp.296,301, April 2007

[39] V. Kumar, K. Rakesh, K. K. Pradeep, "Impedancespectroscopy analysis of oriented and mercerized bamboo fiber-reinforced epoxy composite, “ J Mater Sci, Vol. 46, pp. 3445-51 2011.

[40] P.S. Murherjee, K.G. Satyanarayana, "Structure and properties of some vegetable fibers, part 1. Sisal fiber,“ Journal of Materials Science Vol. 19 pp. 3925-3934, 1984.

[41] E.T.N. Bisanda, M.P. Ansell, "Properties of sisal-CNSL composites," Journal of Materials Science Vol. 27, pp. 1690-1700, 1992.

[42] N. Chand, R.K. Tiwary, P.K. Rohatgi, "Bibliography resource structure properties of natural cellulosic Fibersan annotated bibliography, " Journal of Materials Science, Vol. 23, pp. 381-387, 1988.

[43] A.N. Towo, M.P. Ansell, "Fatigue of sisal fibre reinforced composites: Constant-life diagrams and hysteresis loop capture," Compos Sci Technol, Vol. 68, pp. 915924, 2008.

[44] F.A. Silva, N. Chawlab, R.D.T. Filho, "An experimental investigation of the fatigue behavior of sisal fibers," Mater Sci Eng A, Vol. 516, pp. 90-95, 2009.

[45] B. Ahmed, B. Abderrezak, B. Mostefa, S. Fabrizio, "Tensile static and fatigue behavior of sisal fibres," Materials and Design, Vol. 46, pp. 76-83, 2013.

[46] J. Kuruvilla, V. Siby, G. Kalaprasad, T. Sabu, L. Prasannakumari, K. Peter, C. Pavithran, "Influence of interfacial adhesion on the mechanical properties and fracture behavior of short sisal fibre reinforced polymer composites,“ Eur. Polym. J., Vol. 32, pp. 1243-1250, 1996.

[47] E.T.N. Bisanda, "The effect of alkali treatment on the adhesion characteristics of sisal fibres," Appl Compos 
Mater, Vol. 7, pp. 331-339, 2000.

[48] Z.R. Min, Q.Z. Ming, L. Yuan, C.Y. Gui, M.Z. Han, "The effect of fiber treatment on the mechanical properties of unidirectional sisal-reinforced epoxy composites,“ Composites Science and Technology, Vol. 61, pp. 1437-1447, 2001.

[49] P.A. Sreekumar, P.T. Selvin, M.S. Jean, J. Kuruvilla, G. Unnikrishnan, T. Sabu, "Effect of fiber surface modification on the mechanical and water absorption characteristics of sisal/polyester composites fabricated by resin transfer molding," Composites: Part A, Vol. 40, pp. 1777-1784, 2009.

[50] P.V. Joseph, G. Mathew, K. Joseph, G. Groeninckx, S. Thomas, "Dynamic mechanical properties of sisal fibre reinforced polypropylene composites," Composites: Part A, Vol. 34, pp. 275-290, 2003.

[51] A.A. Vera, V. Analia, "Influence of fiber chemical modification procedure on the mechanical properties and water absorption of materBi-Y/sisal fiber composites," Composites: Part A, Vol. 37, pp. 1672-1680, 2006.

[52] T.K. Jun, N.N. Anil, "Mercerization of sisal fibers: Effects of tension on mechanical properties of sisal fiber and fiber-reinforced composite," Composites: Part A, Vol. 41, pp. 1245-1252, 2010.

[53] S. Supranee, P. Thirawudh, Y. Nantaya, "Mechanical property improvement of unsaturated polyester composite reinforced with admicellar-treated sisal fibers," Composites: Part A, Vol. 40, pp. 687-694, 2009.

[54] Y.L. Koon, B. Puja, J.B. Jonny, B. Alexander, "Short sisal fibre reinforced bacterial cellulose polylactide nanocomposites using hairy sisal fibres reinforcement, “ Composites: Part A, Vol. 43, pp. 2065-2074, 2012.

[55] M. Henriksson, G. Henriksson, L.A. Berglund, T. Lindström, "An environmentally friendly method for enzyme-assisted preparation of microfibrillated cellulose (MFC) nanofibres,“" Eur Polym J, Vol. 43, pp. 34343441, 2007.

[56] T. Zimmerman, E. Pöhler, T. Geiger, "Cellulose fibrils for polymer reinforcement,“ Adv Eng Mater, Vol. 6, pp. 754-761, 2004.

[57] T. Saito, Y. Nishiyama, J.L. Putaux, M. Vignon, A. Isogai, "Homogeneous suspensions of individualized microfibrils from TEMPO-catalyzed oxidation of native cellulose," Biomacromolecules, Vol. 7, pp. 1687-1691, 2006.

[58] X.Z. Lin, Y.F. Shi, S.Z. Xue, Y.Z. Huai, "Effects of surface microfibrillation of sisal fibre on the mechanical properties of sisal/aramid fibre hybrid composites, “ Composites: Part A, Vol. 4, pp. 244-252, 2011.

[59] E.E.M. Ahmad, A.S. Luyt, "Effects of organic peroxide and polymer chain structure on morphology and thermal properties of sisal fibre reinforced polyethylene composites, “ Composites: Part A, Vol. 43, pp. 703-710, 2012.

[60] P.A. Sreekumar, K. Joseph, G. Unnikrishnan, S.A. Thomas, "Comparative study on mechanical property of sisal leaf fibre reinforced polyester composites prepared by resin transfer and compression moulding techniques," Compos Sci Technol, Vol. 67, pp. 453-461, 2007.

[61] P. Antich, A. Vazquez, I. Mondragon, C. Bernal, "Mechanical behavior of high impact polystyrene reinforced with short sisal fibers, “Composites: Part A, Vol. 37, pp. 139-150, 2006.

[62] D.M.J. Jackson, J. Megiatto, G. S. Cristina, C.R. Elaine, F. Elisabete, "Thermoset matrix reinforced with sisal fibers: Effect of the cure cycle on the properties of the biobased composite," Polymer Testing, Vol. 28, pp. 793800, 2009.

[63] J. Kasama, S. Nitinat, "Effect of glass fiber hybridization on properties of sisal fiber-polypropylene composites," Composites: Part B, Vol. 40, pp. 623-627, 2009.

[64] K.P. Noorunnisa, K.H.P.S. Abdul, M. Jawaid, R.G. Ramachandra, N.C. Surya, S.N. Venkata, "Sisal/Carbon Fibre Reinforced Hybrid Composites: Tensile, Flexural and Chemical Resistance Properties," J Polym Environ, Vol. 18, pp. 727-733, 2010.

[65] P. Augustine, J. Kuruvilla, T. Sabu, "Effect of surface treatments on the electrical properties of low-density polyethylene composites reinforced with short sisal fibers," Composite Science and Technology, Vol. 57, pp. 67-79, 1997.

[66] A. Paul, S. Thomas, C. Pavithran, "Electrical properties of natural ®ber reinforced low density polyethylene composites: a comparison with carbon black and glassfibre filled low density polyethylene composites," Journal of Applied Polymer Science, Vol. 63, pp. 247-266, 1997.

[67] P.A. Sreekumar, M.S. Jean, J. Kuruvilla, G. Unnikrishnan, T. Sabu, "Electrical properties of short sisal fiber reinforced polyester composites fabricated by resin transfer molding," Composites: Part A, Vol. 43, pp. 5075112012.

[68] N.M. Sergio, C. Veronica, J.S.R. Ruben, M.M. Frederico, "Thermogravimetric stability of polymer composites reinforced with less common lignocellulosic fibers- an overview," Journal of Materials Research and Technology, Vol. 1, pp. 117-126, 2012.

[69] I.O. Bakare, F.E. Okieimen, C. Pavithran, H.P.S. Abdul Khalil, M. Brahmakumar, "Mechanical and thermal properties of sisal fiber-reinforced rubber seed oil-based polyurethane composites," Materials and Design, Vol. 31, pp. 4274-4280 2010.

[70] J. Rachasit, S. Nitinat, J. Kasama, "Effect of flame retardants on flame retardant, mechanical, and thermal properties of sisal fiber/polypropylene composites," Composites Part: B, Vol. 56, pp. 249-253, 2014.

[71] G. Kalaprasad, P. Pradeep, M. George, C. Pavithran, T. Sabu, "Thermal conductivity and thermal di€usivity analyses of low-density polyethylene composites reinforced with sisal, glass and intimately mixedsisal/glassfibres," Composites Science and Technology, Vol. 60, pp. 29672977, 2000.

[72] A.H. Syed, V. Pandurangadu, K. Palani, "Machinability 
of glass fiber reinforced plastic (GFRP) composite materials," International Journal of Engineering, Science and Technology, Vol. 3, pp. 103-118, 2011.

[73] D.G. Babu, K.S Babu., B.U.M. Gowd, "Optimization machining parameters in drilling hemp fiber reinforced composites to maximize the tensile strength using design experiments," Indian Journals of Engineering and Materials Science, Vol. 20, pp. 385-390, 2013.

[74] S. Veerapuram, M. Nambi, "Optimization of Machinability of Polyester/Modified Jute Fabric Composite Using Grey Relational Analysis (GRA)," Procedia Engineering, Vol. 64, pp. 1003-1012, 2013.

[75] D.G. Babu, K.S. Babu, B.U.M. Gowd, "Effect of Machining Parameters on Milled Natural FiberReinforced Plastic Composites," Journal of Advanced Mechanical Engineering, Vol. 1, pp. 1-12, 2013. 